\title{
Climatic urban design: configuring the urban fabric to support daylighting, passive cooling, and solar heating
}

\author{
R. M. DeKay \\ GreenVision Studio, School of Architecture, Univ. of Tennessee, USA
}

\begin{abstract}
Access to site-based energy resources is a pre-requisite for natural lighting, solar heating, and natural ventilation in buildings. This paper describes design methods and proposals developed for the City of Chattanooga, Tennessee, USA, to simultaneously address access to daylight, solar radiation and wind for as many buildings as possible in the urban core. The study area is the entire downtown district. Results include specific design proposals as part of the city's Downtown Plan along with portable design patterns that may be employed in other cities. The organization of buildings, streets and open spaces in higher density areas can either preserve or block access to sun, wind, and light resources. I developed a composite technique, 'Climatic Envelopes,' which regulates the shape of buildings on a block or site for the purpose of protecting access to both daylight from the sky and direct radiation from sun. It combines the 'Daylight Envelope' with the 'Solar Envelope'. This technique was applied to the existing pattern of blocks and buildings in the downtown core. Results show that existing buildings were not designed to consider other sites' rights to light and sun. My team developed building configurations that satisfy the criteria for composite climatic envelopes and follow several design patterns for daylighting, while maximizing development potential. The resulting calculated floor area ratio for the proposed pattern was twice the existing density. The team developed proposals for modifications to cool the city by creating additional shade, channeling winds to bring ventilation to more buildings, and working with the existing topography, resulting in a 'Downtown Cooling Plan.'

Keywords: daylight access, daylight envelope, solar access, solar envelope, passive solar heating, urban design, climatic envelope, passive cooling, urban cooling, urban microclimate.
\end{abstract}




\section{Introduction}

The GreenVision Studio at the School of Architecture, University of Tennessee, Knoxville was invited by Professor Stroud Watson of the Chattanooga Downtown Planning and Design Centre to develop plans for the environmental component of the city's downtown plan. This paper grows out of a portion of that plan. Our exploration of climatic neighbourhoods is a part of the recommendations for green neighbourhoods, one of five within the plan [1].

We defined a green neighbourhood as one that 1) connects people to their natural and social communities, 2) preserves the health of both the natural and the social neighbourhood, 3) expresses a unique, local sense of place, and 4) helps to build the district and city of which it is a part. Green design patterns can improve both social and environmental quality.

The city is built out of the incremental actions of thousands of individuals over time. To create a living, green city a shared language of common, accessible design patterns can be employed repeatedly. The team proceeded from the theory that these patterns include patterns for energy, transportation, the water cycle, wildlife habitat, food and nutrients, materials and social processes. This paper focuses on patterns for access to renewable site energy.

\section{Climatic neighbourhoods}

We will be identifying some important design patterns for a neighbourhood designed with the climate. A design pattern is a suggested generalized solution to a recurring design problem, stated in such as way that the exact built pattern can be done in many possible ways. Design patterns usually offer suggestions (such as size, shape, location and organization) about the relationships among physical components such as buildings, outdoor spaces, vegetation and streets. In what follows, specific patterns are indicated in SMALL CAPS.

The organization of buildings, streets and open spaces, particularly in higher density areas, can either preserve or block access to sun, wind and light resources. In this case, we were interested in what the form of the city would be like if we adapted the existing pattern of development to better provide access to the site resources of sun, wind and light that are necessary for passive heating, cooling and lighting of buildings. We took the existing city street grid and legal property divisions as a starting point for generating forms that would give access to all three forces.

\section{Climatic envelopes: construction process}

CLIMATIC ENVELOPES regulate the shape of buildings on a block or site for the purpose of protecting access to the valuable resources of sky and sun on adjacent blocks or sites [2]. Access to daylight and solar energy resources is a prerequisite for natural lighting and solar heating of buildings.

In urban situations, as the height of buildings along streets increases, the daylight available to buildings, especially on lower floors, is decreased. If a 
building to the south of another is too tall, it will block the winter sun. A composite CLIMATIC ENVELOPE is the maximum developable volume that will allow access to both direct beam radiation (sun) and the diffuse sky (light). It is a combination of two techniques, the DAYLIGHT ENVELOPE [1] and the SOLAR ENVELOPE [2]. The examples on the following pages show the construction of envelopes for a single block in downtown Chattanooga. These maximum development envelopes have been applied to an entire block at once. The same technique can be applied on a parcel basis, resulting in much smaller allowable building volume.

\subsection{Daylight envelope criteria}

The amount of light that reaches a window is primarily determined by the sector of the sky that it can "see," as represented by the sky view angle (fig. 1). The sky view angle required to provide a given level of daylight at the building façade generates the sky exposure plane. In practice, a regulating sky exposure angle is often used in development rules. The criterion chosen for our study is based on the daylight factor in rooms on the lower floor that will supply $20 \mathrm{fc}$ (215 lux) for $85 \%$ of annual hours between 9 AM and 5 PM. Many other criteria could also be used. Alternate criteria would generate a different volumetric geometry.

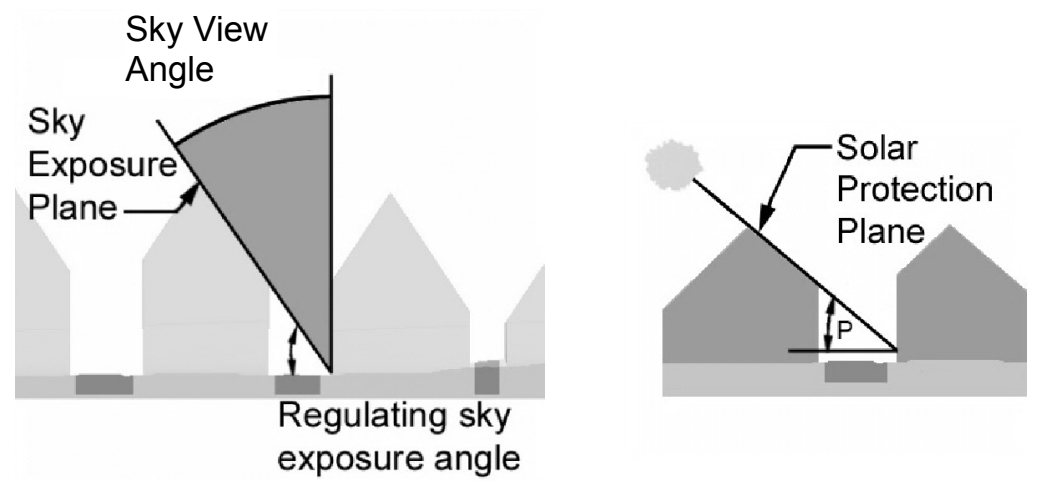

Figure 1: $\quad$ Sky exposure plane (left) and solar protection plane (right).

\subsection{Solar envelope criteria}

The criterion used to generate the SOLAR ENVELOPE is December 21 from $10 \mathrm{AM}$ to $2 \mathrm{PM}$, for floors above the ground floor. Many other criteria could also be used, and as in the daylight envelope, alternate criteria would generate a different volumetric geometry. The sun angle during these times generates the solar protection plane (fig. 1). The profile angle, $P$, is used to regulate the plane. The profile angle is the sun's altitude angle at a specified time translated to an azimuth angle perpendicular to the block face. 


\subsection{Envelope construction process}

To construct a DAYLIGHT ENVELOPE, follow the steps in fig. 2. More extensive details of the method are given in DeKay [3] and in Sun, Wind \& Light [5].
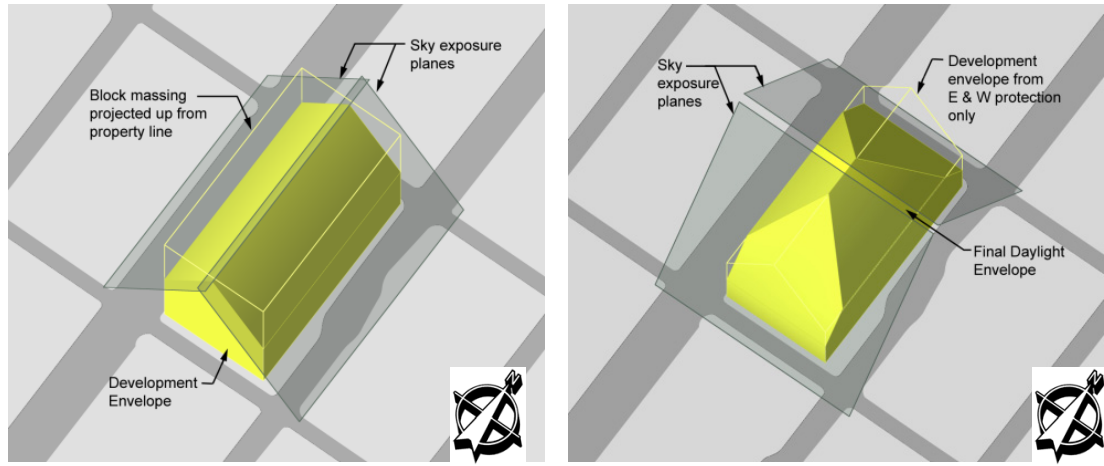

Figure 2: Constructing the daylight envelope. Step 1: sky exposure planes applied to east and west block faces create a gable-roof shaped development envelope (left). Step 2: further application of skyexposure planes to the north and south block faces create a hip-roof shaped development envelope. The hip on the north end of the block preserves access for the south facing side of the adjacent block (right).

To construct a SOLAR ENVELOPE, follow the steps in fig. 3. More extensive details of the method are given by Knowles [4] and in Sun, Wind \& Light [5].
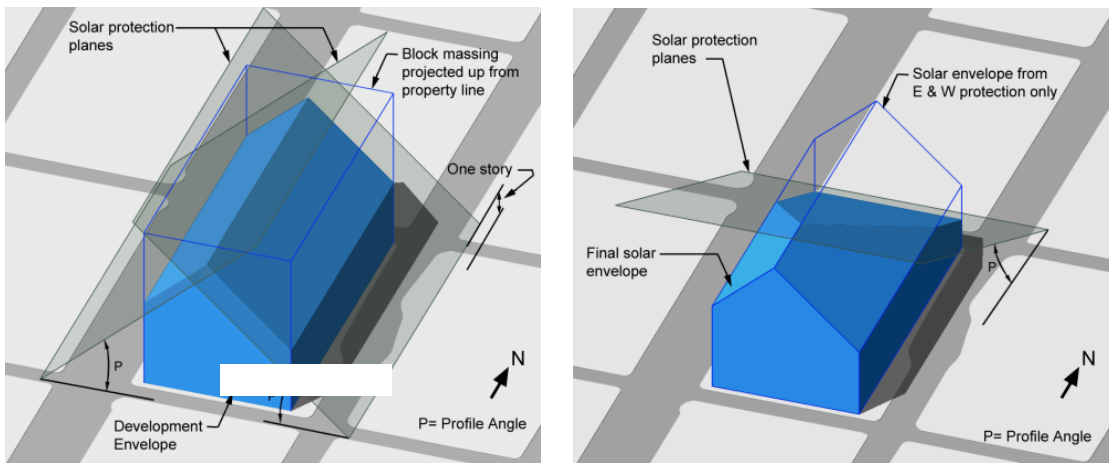

Figure 3: Constructing the solar envelope. Step 1: solar protection planes tilted at the profile angle $(P)$ are applied to the east and west block faces to create a gable-roof shaped development envelope (left). Step 2: the completed solar protection plane (protecting neighboring blocks) is tilted at the profile angle along the north block face to yield a complete solar envelope with a hip-roof form at the north end (right). 
The CLIMATIC ENVELOPE is the intersection of the two volumes, taking the lesser volume that is common to both solar and daylight envelopes, as shown in fig. 4. More extensive details of the method are given in the forthcoming Third Edition of Sun, Wind \& Light: architectural design strategies [2].
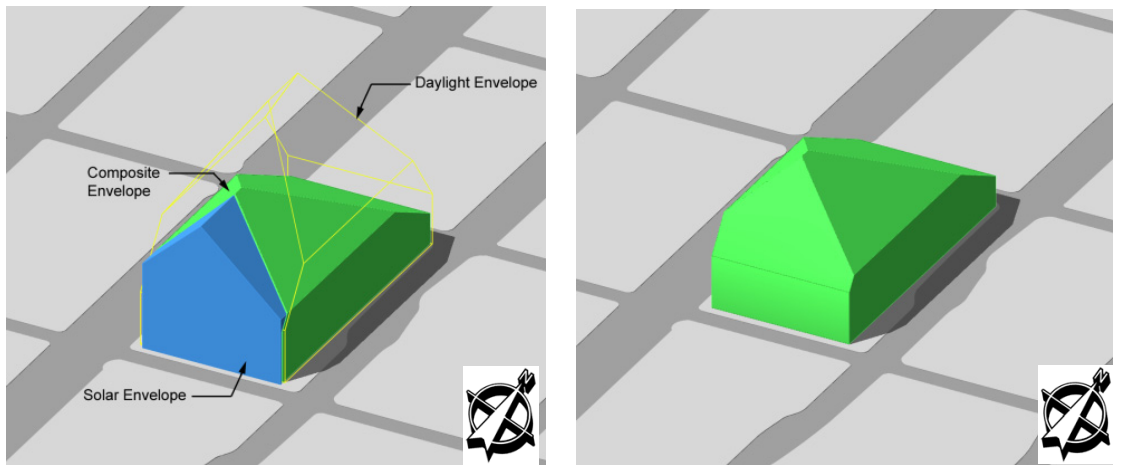

Figure 4: Forming the climatic envelope. Step 1: the two envelopes are intersected and a composite envelope is generated by selecting only the volume contained within both. In this example, the solar envelope fits within the daylight envelope, except on the south end of the block (left). Step 2: the final composite envelope shows the solar envelope mass reduced by the influence of the daylight envelope along the south end. The new climatic envelope will provide access for surrounding blocks to both diffused daylight from the sky and direct beam sunlight (right).

\section{Climatic envelopes: urban pattern}

This section explores daylight and solar envelope techniques applied to the core of downtown Chattanooga and combined to form composite CLIMATIC ENVELOPES. The size and geometry of the envelopes varies with the block size and orientation.

There are several factors that affect the amount of natural light that reaches a building façade. Besides the local climate, the most important is the ratio between the building heights and the street right-of-way width between buildings. In addition, the reflectance of the exterior building materials and ground surfaces, along with the area of windows in the façade, also influence the level of daylight available. Fig. 5 shows the DAYLIGHT ENVELOPE concept applied to multiple blocks.

For the SOLAR ENVELOPE, east and west block faces are similar in height, while the south facing sides, because the sun comes from that direction in the winter, are taller than the north faces. Note that the SOLAR ENVELOPES, as usually is the case, are smaller on average than the DAYLIGHT ENVELOPES. Fig. 5 shows the SOLAR ENVELOPE concept applied to multiple blocks (detailed excerpt of the district). 

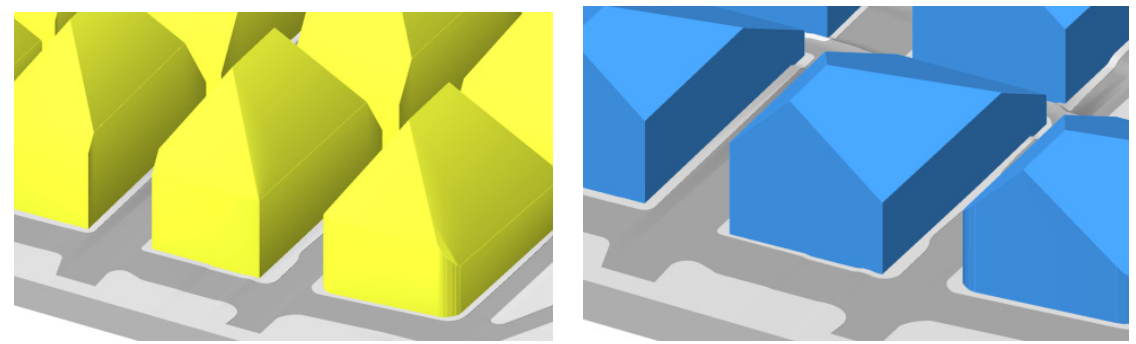

Figure 5: Daylight (left) and solar (right) envelope patterns (detail excerpt).

The final composite CLIMATIC ENVELOPES (fig. 6) show the SOLAR ENVELOPE mass reduced by the influence of the DAYLIGHT ENVELOPE along the south end. The new CLIMATIC ENVELOPES will provide access for surrounding blocks to both diffused daylight from the sky and direct beam sunlight.

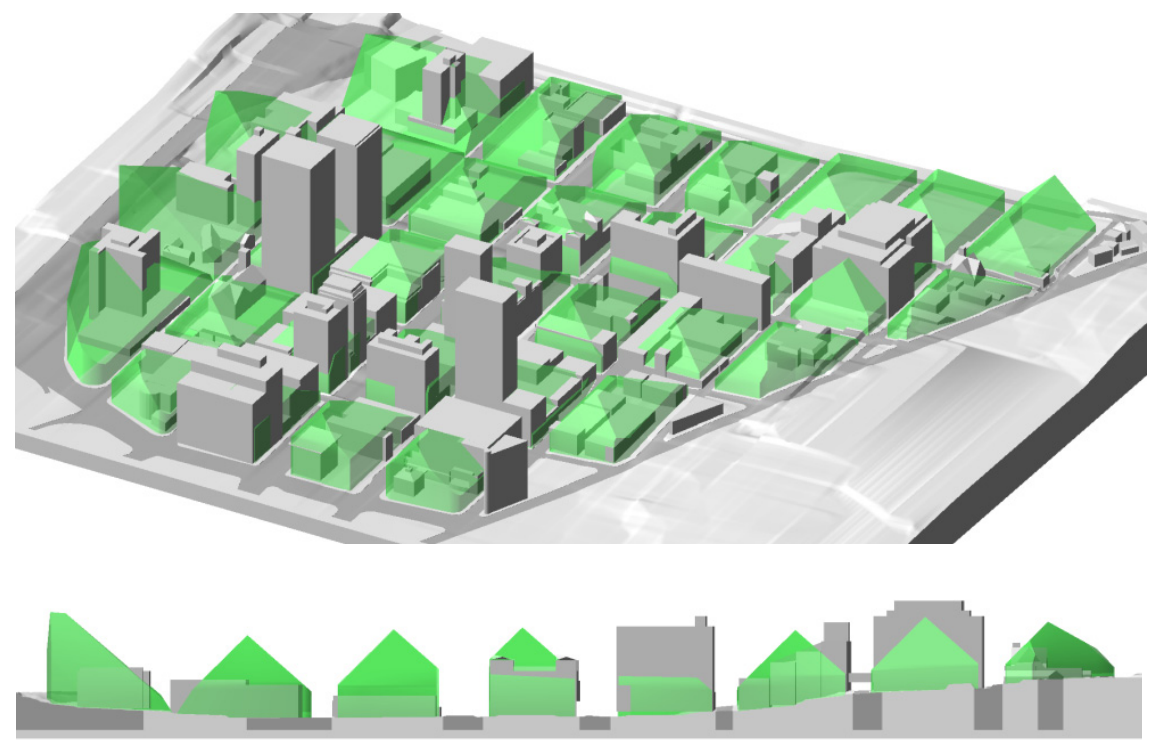

Figure 6: Composite CLIMATIC ENVELOPES, overlaid on existing building volumes, view from southeast and section looking north.

Within the DAYLIGHT ENVELOPE, buildings can be taller on the wider streets. Relatively large buildings can be built within the SOLAR ENVELOPE, with greater height at the center of blocks and on their south ends. Because the composite CLIMATIC ENVELOPE is smaller than either of the other envelopes alone, more existing buildings violate it.

In the future, as fossil fuels are depleted and become increasingly expensive, rights to solar access will also become more important. Since solar technology is cost-effective and available today, and since buildings last a very long time, it is 
important to plan now for a renewable energy future. Once CLIMATIC ENVELOPES are implemented, solar and daylighting rights could be traded. If an owner wanted to build beyond the envelope, they might be required to pay surrounding building owners for the value of solar energy lost over the building's lifetime.

\section{Climatic envelopes: development potential}

The existing floor area ratio (FAR), a measure of development intensity, is about 7.4 in downtown Chattanooga. Maximum development filling the CLIMATIC ENVELOPES would allow a FAR of 15.3, while buildings with good daylighting, shown in fig. 7, still achieve a FAR of 10.8 , an increase of $45 \%$ over the current FAR. The drawings show possible building configurations within the composite envelopes following several daylighting design rules, while maximizing development potential. Buildings in the study, generated by three graduate students, follow one of two patterns: buildings with thin plans of 50-70 ft (15$21 \mathrm{~m}$ ) thick or buildings with light courts and atria.

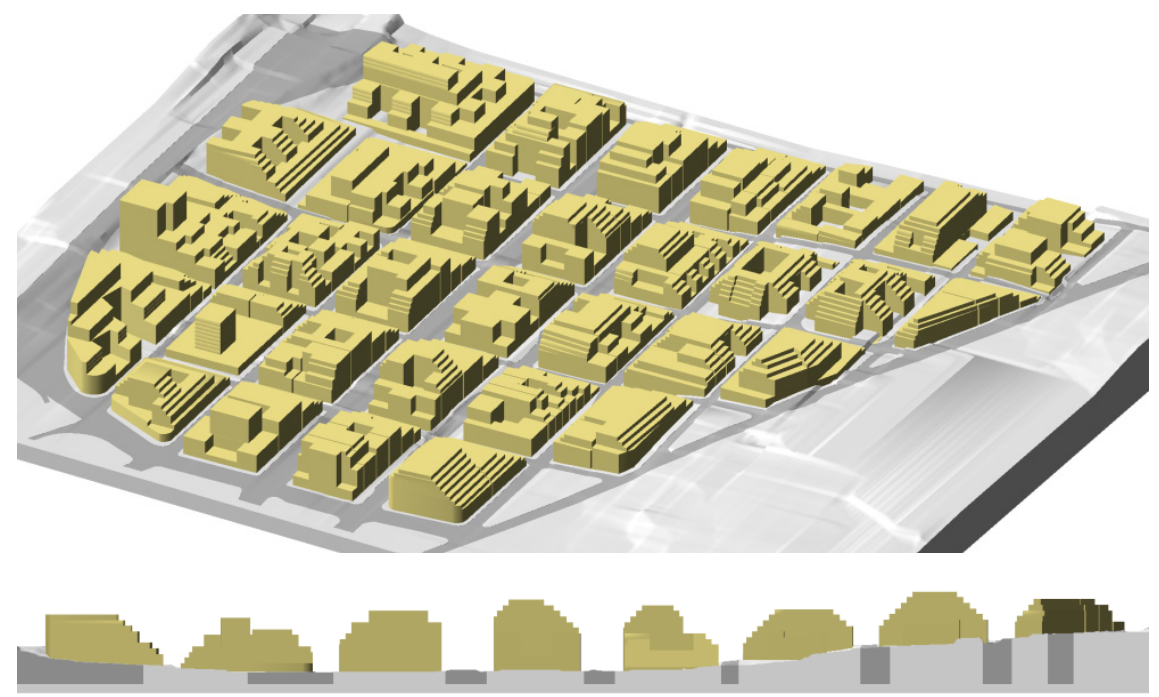

Figure 7: Maximum daylighted buildings volumes within CLIMATIC ENVELOPES, view from southeast and section looking north.

Peaks of the envelope have been cut off where the size of the floor under the envelope was too small to be practically occupied. Light courts are shown without roofs, but could be glazed as atria. Often we have located light courts with an open side to the south, allowing for a sunny, wind-protected roof garden in winter. If the southern side of an atrium is lower than the north side it also works better as a solar heat collector for the building (a sunspace system).

Finally, we have added some randomness based on the underlying parcel sizes and configurations and on patterns of existing development. We treated 
some blocks as a single large building, others as two large sites and some as composed of several smaller parcels.

\section{Urban cooling}

The design of a city can make the outdoor climate more intense and uncomfortable or more moderate and comfortable. The effect of city design on microclimate can make air quality worse and buildings more expensive to operate - or it can help clean the air and help buildings to be more energy efficient. Urban development replaces vegetation with asphalt and buildings. Cool, transpiring green surfaces are replaced with heat-absorbing dark surfaces, such as black roofs and heat-storing massive surfaces, such as concrete. Taller buildings in the inner city block the wind, create more friction for the wind, and reduce the ability of other buildings to lose heat to the night sky. This causes the urban heat island effect in which central city temperatures are significantly hotter than the surrounding countryside. High summer temperatures increase energy costs and health risks.

If the streets are not oriented properly to the prevailing winds, then not all streets will receive good ventilation. Dense connected buildings with few gaps in between push the wind up over the city, instead of allowing it to penetrate and disperse around every building. When the air of the city is not vented out, heat and pollutants build up, especially at the street level. When wind is not well dispersed throughout the urban fabric, many buildings and outdoor spaces do not have access to breezes. Therefore, they can not be cooled by the wind. Because the buildings do not have wind access, air-conditioning is often used when natural cross-ventilation would do the job. Air-conditioners simply move the heat from inside, along with their own waste heat, to the outside, where it is rejected to the atmosphere, thus further warming the outdoor climate.
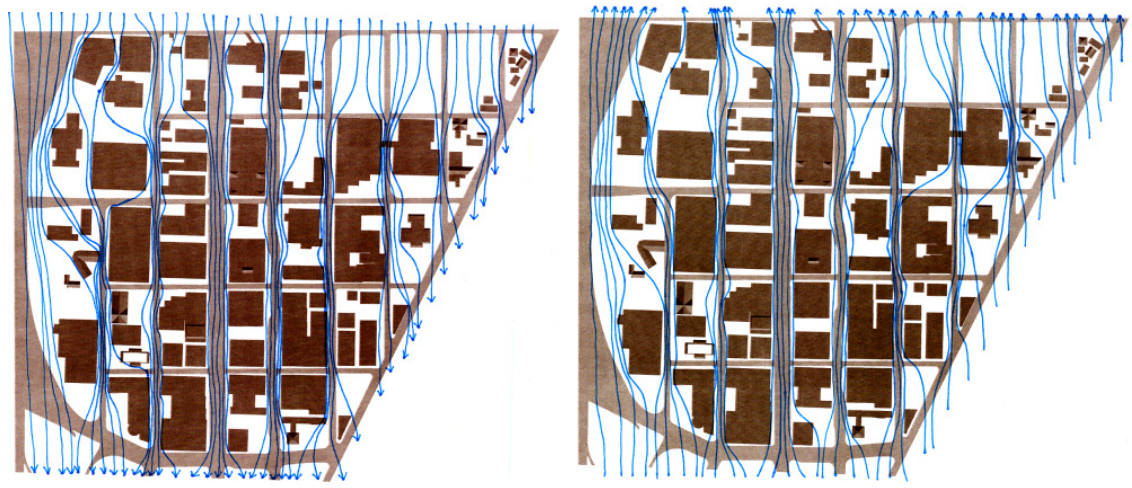

Figure 8: Wind patterns; from north in winter (left), south in summer (right). 


\subsection{Urban wind patterns}

The diagrams in fig. 8 show an analysis of wind patterns in downtown Chattanooga. The prevailing north-south wind direction is channeled by wide north-south streets and narrow blocks that face the wind. This creates faster winds on these streets and much slower winds on east-west streets. The effect is relatively poor ventilation of streets and poor wind access to buildings for use of natural ventilation. Basic principles of wind behavior were applied to modify the prevailing directions based on urban patterns near the ground.

\section{The Chattanooga urban cooling plan}

The cooling plan has two objectives:

1) The reduction of the urban heat island effect by shading and vegetation evapotranspiration. Trees shade the ground and buildings, and all vegetation performs a type of local evaporative cooling.

2) The more equitable redistribution of breezes throughout the downtown core, allowing building ventilation and improving pedestrian comfort.

Chattanooga's north-south winds, combined with downtown's pattern of long north-south blocks, narrower east-west streets and dense, solid masses of buildings makes the existing condition very poor for ventilation and exacerbates the uncomfortable outdoor conditions. However, there are better, modified urban patterns that can ameliorate much of the problem.

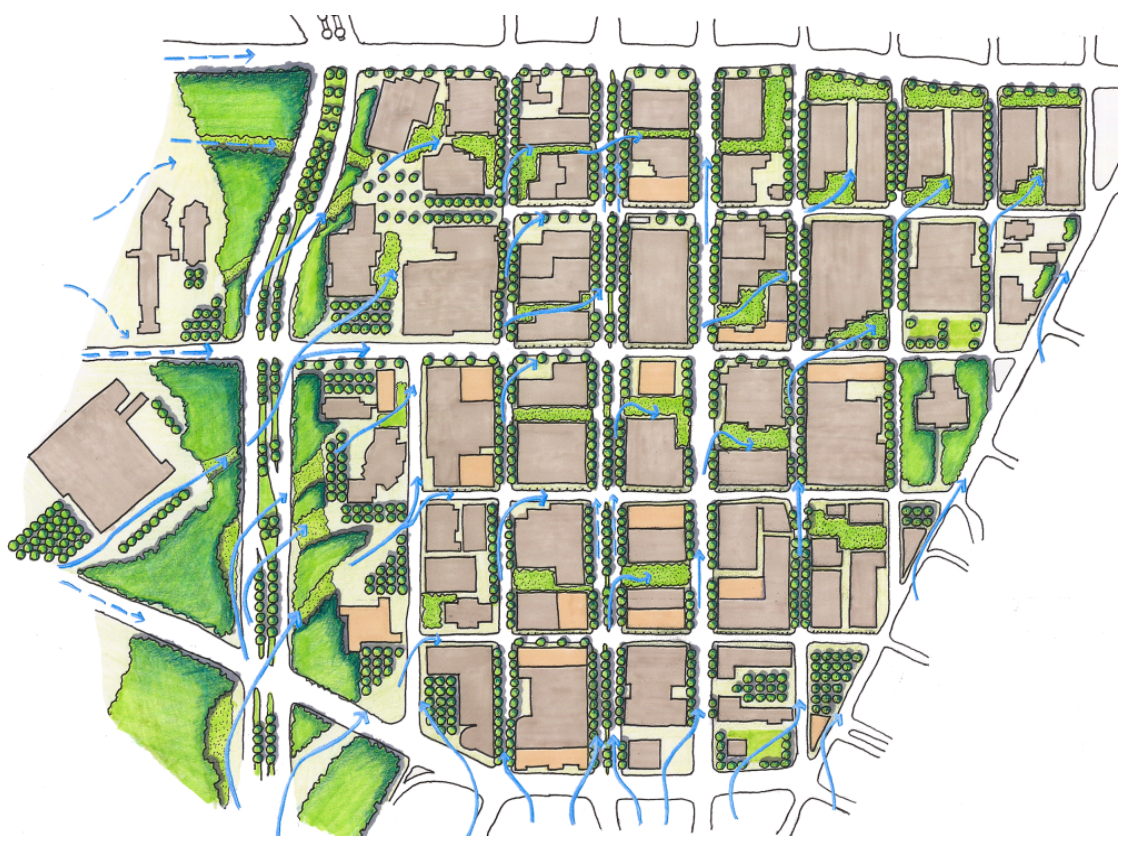

Figure 9: Urban cooling plan for the downtown core. 
The plan in fig. 9 shows an integration of numerous urban design strategies to create a cooler summer microclimate and to help distribute winds to more buildings. The individual concepts are explained below. There are three basic ideas to this approach:

- Cool the city by increasing dispersed vegetation.

- Disperse wind throughout the urban fabric by creating passages in the middle of blocks and between buildings.

- Disperse wind throughout the urban fabric by using landscaping and open space patterns to direct wind.

\section{Cooling design patterns}

The following patterns were employed in creating the cooling plan:

DISTRIBUTED VEGETATION: Street trees, parking orchards and planted surfaces - all forms of DISTRIBUTED VEGETATION - cool the urban microclimate (fig. 10). Trees shade the ground, light colors reflect heat and vegetation cools the air around it by evaporation. Temperature reduction is proportional to vegetation cover. In addition to forest patches and small parks, the diagram shows parking orchards and street orchards.
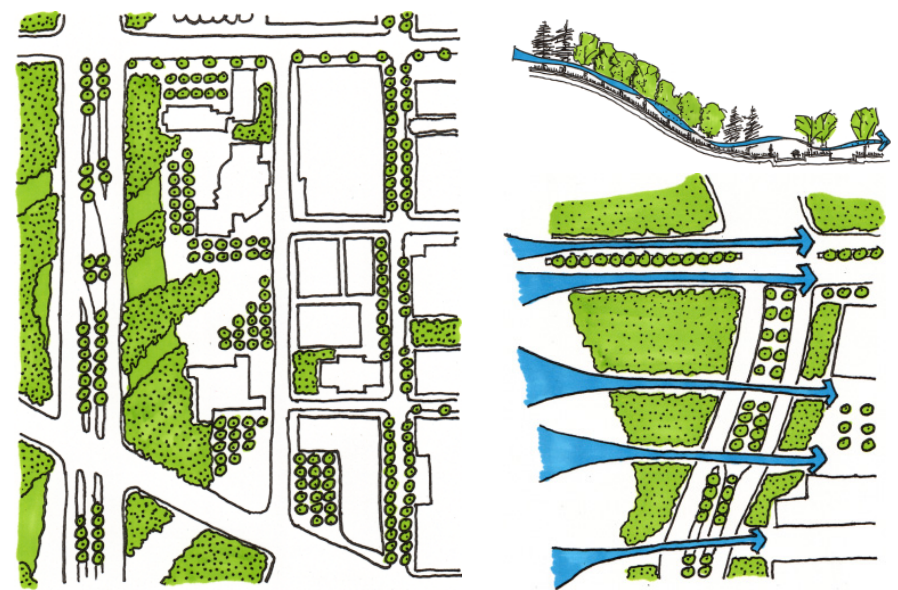

Figure 10: Distributed vegetation (left) and upslope forest drainage (right).

UPSLOPE FOREST DRAINAGE: Green ventilation corridors direct cool air drainage from upslope into the hot urban core in a pattern we call UPSLOPE FOREST DRAINAGE (fig. 10). At night when winds are slower, cooler denser air flows downhill from the vegetated slopes of Cameron Hill, venting out hotter, polluted air in the city center. Protecting these slopes from development is critical to this strategy.

BREEZE CHANNELS: Spaces between buildings can be organized to create BREEZE CHANNELS (fig. 11). North-south alleys and breaks in between buildings 
promote dispersion. Greater block permeability balances positive and negative wind pressure, thus improving building and public space ventilation. East-west pedestrian passages allow wind to penetrate long block faces. Greater block permeability increases east-west air movement. Mews create more building corners and more frontages for housing.
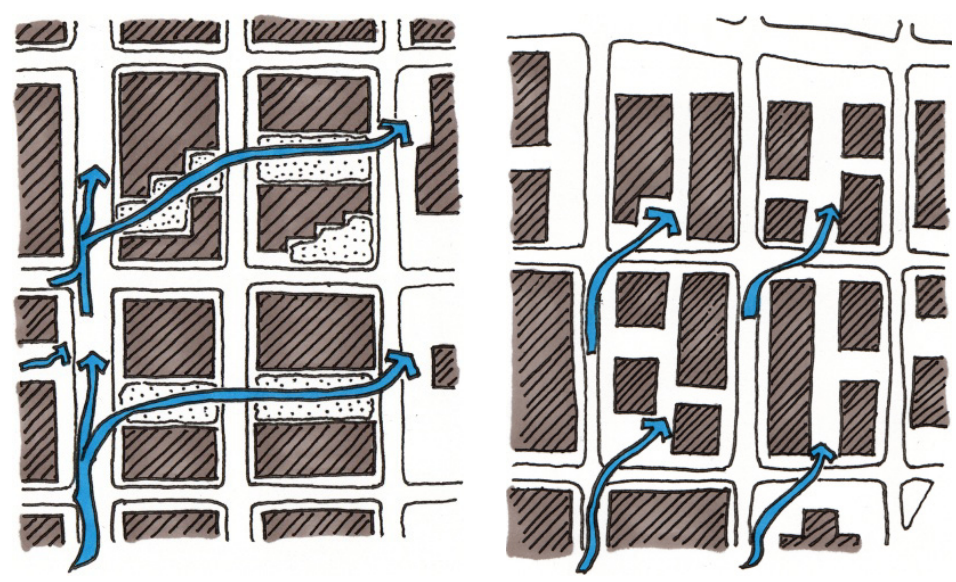

Figure 11: North-south BREEZE CHANNELS (right) and east-west BREEZE CHANNELS (left).

INTERWOVEN BUILDINGS AND PLANTING: A high proportion of vegetation between and around buildings can cool the ambient temperature. Many smaller green spaces have a greater effect on surrounding temperatures than fewer larger spaces. The green spaces shown here use existing vacant land and connect to form a pedestrian network (fig. 12).
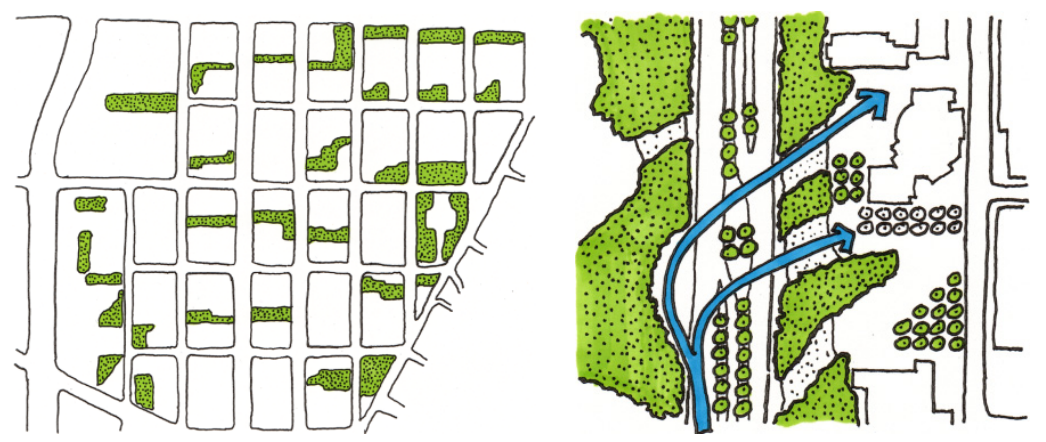

Figure 12: Interwoven buildings and planting (left) and landscaping redirection (right).

LANDSCAPING REDIRECTION: Boulevard planting and site landscaping can be used for re-directing wind into breeze channels - in this case toward east-west 
BREEZE CHANNELS (fig. 12). Dense vegetation makes a good windbreak and proper positioning can create a combination of positive and negative pressures that can make use of winds that would otherwise strike buildings at an acute angle and ordinarily bypass ventilation openings in façades.

\section{Conclusion}

The organization of buildings, streets and open spaces can either preserve or block access to sun, wind and light resources. A network of relatively simple design patterns are available to incorporate into urban development planning and regulation instruments, that if implemented now, will provide for buildings the site-based energy resources they will require in the coming renewable energy economy.

The author gratefully acknowledges assistance from Cassius Moter IV.

\section{References}

[1] DeKay, M., Moir-McClean, T., \& Rothman R., GreenCenter: Planning for Environmental Quality in Chattanooga, a report to the Chattanooga Downtown Planning and Design Center. 200 pp., 2003.

[2] Brown, G. Z. and DeKay, M., Sun, Wind, \& Light: Architectural Design Strategies, 3rd ed. New York: John Wiley, 2012, forthcoming.

[3] DeKay, M., Daylighting and urban form, an urban fabric of light, Journal of Architecture and Planning Research. 27 (1), Spring, pp. 35-56, 2010.

[4] Knowles, R. L. Sun Rhythm Form. Cambridge, Mass: MIT Press, 1981.

[5] Brown, G. Z. \& DeKay, M., Sun, Wind, \& Light: Architectural Design Strategies, 2nd edition. New York: John Wiley, 2001. 